\title{
Changes in Excitability of Ascending and Descending Inputs to Cerebellar Climbing Fibers during Locomotion
}

\author{
Joanne Pardoe, ${ }^{1}$ Stephen A. Edgley, ${ }^{2}$ Trevor Drew, ${ }^{3}$ and Richard Apps ${ }^{1}$ \\ ${ }^{1}$ Department of Physiology, School of Medical Sciences, University of Bristol, Bristol, BS8 1TD, United Kingdom, ${ }^{2}$ Department of Anatomy, University of \\ Cambridge, Cambridge, CB2 3DY, United Kingdom, and ${ }^{3}$ Department de Physiologie, Universite de Montreal, Montreal, Quebec, Canada H3C 3J7
}

The inferior olive climbing fiber projection plays a central role in all major theories of cerebellar function. Therefore, mechanisms that control the ability of climbing fibers to forward information to the cerebellum are of considerable interest. We examined changes in transmission in cerebro-olivocerebellar pathways (COCPs) and spino-olivocerebellar pathways (SOCPs) during locomotion in awake cats $(n=4)$ using low-intensity electrical stimuli delivered to the contralateral cerebral peduncle or the ipsilateral superficial radial nerve to set up volleys in COCPs and SOCPs, respectively. The responses were recorded as evoked extracellular climbing fiber field potentials within the $\mathrm{C} 1$ or $\mathrm{C} 3$ zones in the paravermal cerebellar cortex (lobule $\mathrm{Va}-\mathrm{Vc}$ ). At most $\mathrm{C} 1$ and $\mathrm{C} 3$ zone sites, the largest COCP responses occurred during the stance phase, and the smallest responses occurred during the swing phase of the ipsilateral forelimb step cycle. In marked contrast, SOCP responses recorded at the same sites were usually largest during the swing phase and smallest during the stance phase. Because substantial climbing fiber responses could be evoked in all phases of the step cycle, the results imply that olivary neurons remain excitable throughout, and that the differences between SOCPs and COCPs in their pattern of step-related modulation are unlikely to have arisen solely through inhibition at the level of the inferior olive (e.g., by activity in the inhibitory cerebellar nucleo-olivary pathway). The different patterns of modulation also suggest that climbing fiber signals conveyed by COCPs and SOCPs are likely to affect information processing within the cerebellar cortical $\mathrm{C} 1$ and $\mathrm{C} 3$ zones at different times during locomotion.

Key words: cerebellum; inferior olive; gating; cerebellar cortex; motor control; climbing fiber

\section{Introduction}

The inferior olive climbing fiber (CF) projection to the cerebellum plays a critical but enigmatic role in motor control. Uncertainty regarding the information encoded in this pathway (for review, see Simpson et al., 1996) has arisen partly because of the difficulty of identifying the behavioral conditions in which the discharge of complex spikes by cerebellar Purkinje cells (generated by activity in CFs) can be reliably activated. Complex spikes are highly sensitive to sensory stimuli in the passive animal, but during active movements, similar stimuli usually fail to reliably elicit a response (Kolb and Rubia, 1980; Bauswein et al., 1983; Gellman et al., 1985; Andersson and Armstrong, 1987; Armstrong et al., 1988). This has been interpreted as evidence for the operation of a gating mechanism, regulating the time during active movements when information can be forwarded to the cerebellar cortex via the olivocerebellar system.

To date, studies of this phenomenon have been restricted to changes in transmission in ascending spino-olivocerebellar pathways (SOCPs) (for review, see Apps, 1999). During locomotion, for example, transmission in SOCPs relaying signals from the

Received Aug. 22, 2003; revised Dec. 18, 2003; accepted Dec. 19, 2003.

This work was supported by a Canadian Medical Research Council Travelling Fellowship granted to S.A.E. and by the Medical Research Council (R.A., J.P.). We thank Rachel Bissett and Clare Everard for their technical assistance.

Correspondence should be addressed to Dr. Richard Apps, Department of Physiology, School of Medical Sciences, University of Bristol, University Walk, Bristol, BS8 1TD, UK. E-mail: r.apps@bristol.ac.uk.

DOI:10.1523/JNEUROSCI.1659-03.2004

Copyright $\odot 2004$ Society for Neuroscience $\quad$ 0270-6474/04/242656-11\$15.00/0 forelimbs to the $\mathrm{C} 1$ and $\mathrm{C} 3$ zones in lobule $\mathrm{V}$ has been shown to be step-phase dependent. CF responses evoked by ipsilateral forelimb stimulation exhibit greatest and least excitability during the swing and stance phases, respectively, in the ipsilateral forelimb step cycle (Lidierth and Apps, 1990; Apps et al., 1995; Apps and Lee, 1999; also see Horn et al., 1996; Smith and Chapin, 1996).

The site(s) at which these changes in excitability occur remains unknown, although a major candidate is the cerebellum itself: the cerebellar nuclei have a topographically organized inhibitory projection to the inferior olive, raising the possibility that during active movements, the nucleo-olivary pathway controls its excitability (Gibson et al., 1996; Hesslow and Ivarsson, 1996; Ruigrok, 1997; de Zeeuw et al., 1998; Teune et al., 1998).

A large number of descending cerebro-olivocerebellar pathways (COCPs) are also known to exist, converging on the same olivary neurons that supply CFs to the same cortical zones as the SOCPs (Miller et al., 1969; Andersson and Nyquist, 1983; Andersson, 1984a). It is not known whether COCPs are also subject to changes in excitability during movement, and the pattern of any such modulation has important implications relating to the level of operation of the gating mechanism.

The aim of the present study was to compare step-related changes in transmission in COCPs and SOCPs targeting the same cerebellar cortical sites in the paravermal $\mathrm{C} 1$ and $\mathrm{C} 3$ zones in awake, behaving animals. The experiments were conducted independently in two laboratories, but the results were very similar: the pattern of step-related modulation in SOCPs and COCPs 
targeting individual cerebellar recording sites can differ substantially. This implies that the modulation is not attributable solely to inhibition within the olive (e.g., by activity in the nucleoolivary pathway), and that cerebral and spinal paths are likely to forward $\mathrm{CF}$ information to the $\mathrm{C} 1$ and $\mathrm{C} 3$ zones at different times during locomotion. For preliminary communications, see Apps (1999) and Apps and Pardoe (2001).

\section{Materials and Methods}

Results were obtained from experiments using four purpose-bred adult male cats $(4.5-5 \mathrm{~kg})$. Three experiments were conducted at the Department of Physiology of the University of Bristol (under the regulations of the UK Home Office and in accordance with the UK Animals Scientific Procedures Act of 1986), while the fourth was conducted at the Department of Physiology of the University of Montreal (following the guidelines of the Canadian Medical Research Council, with the approval of the University of Montreal Animal Ethics Committee). The procedures for all four experiments were similar, except where stated below.

Animals, training, and surgical procedures. Animals were selected on the basis of their cooperative nature and their ability to walk steadily on a moving belt. Initially, they were trained over a period of 4-6 weeks to walk on the belt at a rate between 0.35 and $0.5 \mathrm{~m} / \mathrm{sec}$ for a minimum of 10 $\mathrm{min}$. At such walking speeds, the duration of each step cycle was between 0.8 and $1.0 \mathrm{sec}$. No aversive training techniques were used. On the contrary, cats were rewarded with food after completion of a successful bout of walking. At the end of each training (or recording) session, each animal was returned to a housing facility shared with other purpose-bred cats.

All surgical procedures were performed under general anesthesia. In three animals (BW3, BW4, and ME1), the anesthetic was sodium pentobarbitone (40 mg/kg, i.p.; Sagatal; Rhone Merieux, Harlow, UK) (maintained with doses administered intravenously as required), while in the fourth animal (BW5), an initial dose of medetomidine hydrochloride $(0.12 \mathrm{mg} / \mathrm{kg}$, s.c.; Domitor; Pfizer, Kent, UK) was given, followed by a continuous infusion of propofol $(0.05 \mathrm{ml} / \mathrm{min}$, i.v.; Rapinovet; ScheringPlough, Union, NJ). In all animals, a single dose of atropine sulfate $(0.5$ $\mathrm{ml}$, s.c.; Animalcare, Dunnington, UK) was administered to reduce secretions, and a wide-spectrum antibiotic was given prophylactically $(0.2$ $\mathrm{mg} / \mathrm{kg}$ ampicillin or $0.5 \mathrm{mg} / \mathrm{kg}$ ayercillin).

Throughout surgery, the temperature of each animal was monitored and maintained within physiological limits by a thermostatically controlled electrically heated blanket. As a precautionary measure, analgesia was maintained postoperatively for $24 \mathrm{hr}(0.08 \mathrm{ml} / \mathrm{kg}$ carprofen, $0.005-$ $0.01 \mathrm{mg} / \mathrm{kg}$ buprenorphine, or $0.05-0.1 \mathrm{mg} / \mathrm{kg}$ butorphanol). The animals were monitored continuously during their recovery and checked twice daily thereafter. No signs of discomfort were visible at any time during the experiments.

Implantables. Figure 1 shows a schematic diagram of the experimental arrangements. After training was complete, implantation of limb and CNS recording and stimulating electrodes was conducted during one aseptic operation or during two aseptic operations in two animals (in the latter instance, each operation was spaced $7 \mathrm{~d}$ apart). The following implants were made into the ipsilateral forelimb: bipolar stimulating and recording electrodes $(0.3-\mathrm{mm}$-diameter Teflon-insulated multistranded stainless steel; Cooner, Chatsworth, CA) around the superficial radial (SR) nerve and bipolar recording electrodes into the lateral head of the extensor muscle triceps brachii (animals BW3-BW5) or into the flexor muscle cleidobrachialis and other muscles (animal ME1). In addition, bipolar stimulating electrodes were implanted around the contralateral SR nerve. All leads were fed subcutaneously to connectors that were attached to the skull with dental acrylic cement, forming a lightweight headpiece. For additional details of the methods, see the research of Apps et al. (1990), Drew (1993), and Apps and Lee (1999).

Cerebellar recording arrangements. A small craniotomy was made on the left (ipsilateral) side to expose the dorsal surface of the cerebellar cortex in the region of the anterior lobe paravermis (lobule V). In the three Bristol experiments (BW3-BW5), a total of 20-24 low-impedance $(32-77 \mathrm{k} \Omega$ at $1 \mathrm{kHz})$ platinum-iridium $(90: 10 \%) 35-\mu$ m-diameter
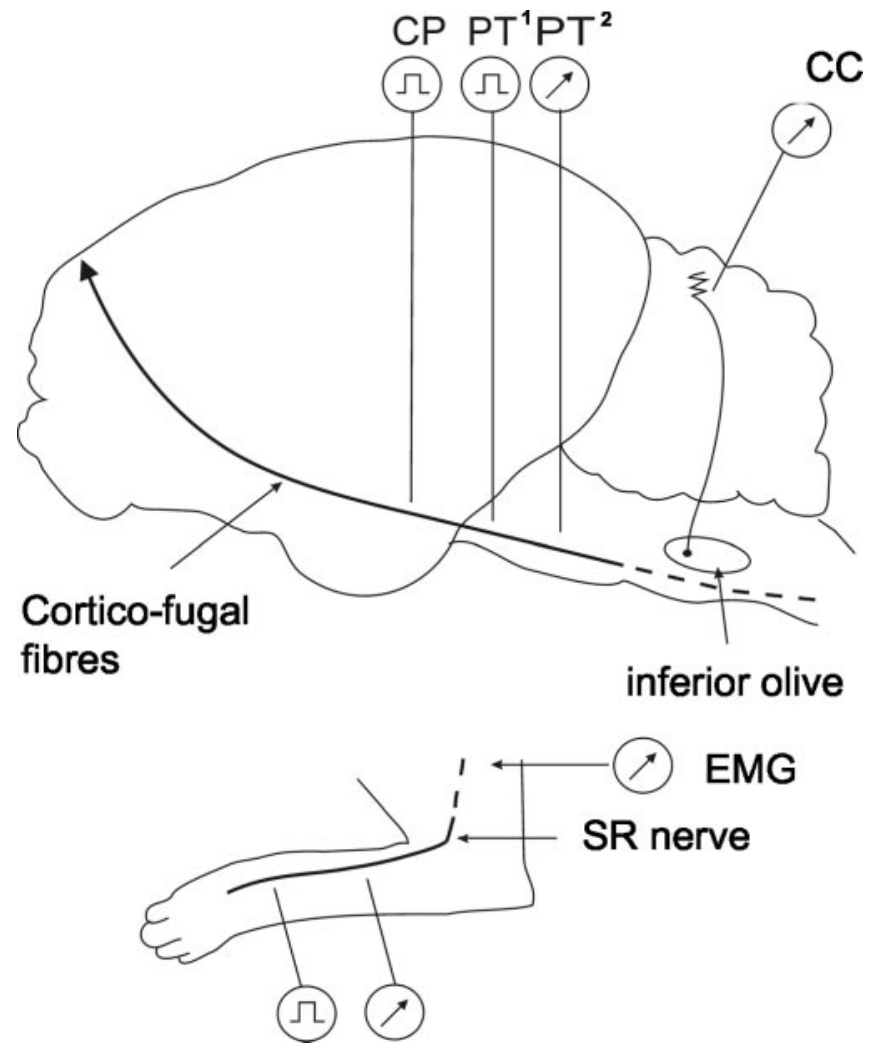

Figure 1. Schematic diagram showing experimental arrangements. Climbing fiber field potentials were recorded from the paravermal cerebellar cortex (CC) (lobule V, zones $\mathrm{C} 1$ and $\mathrm{C} 3$ ). Ascending climbing fiber pathways (SOCPS) were activated by electrical stimuli delivered to the SR nerve in the ipsilateral forelimb, and the afferent nerve volley was monitored proximally. Descending climbing fiber pathways (COCPs) were activated by electrical stimuli delivered to the contralateral CP (all animals) or contralateral pyramidal tract $\left(\mathrm{PT}^{1}\right)$ (animal ME1), and the tract volley was monitored caudally ( $\mathrm{PT}^{2}$ ) (animal BW5). EMG activity was monitored from triceps brachii or cleidobrachialis in the ipsilateral forelimb. See Materials and Methods for additional details.

Teflon-coated microwires (AM Systems, Everett, WA or California Fine Wire, Grover Beach, CA) were inserted to a depth of $\sim 1-2 \mathrm{~mm}$ below the cortical surface. The exposed cerebellar surface was covered with Spongostan (Johnston and Johnston, Ascot, UK) and sealed with dental acrylic (Apps et al., 1995). In the Montreal experiment (ME1), a lightweight stainless-steel recording chamber was fixed to the skull over the craniotomy and centered $4 \mathrm{~mm}$ lateral to the midline to allow access to the same region of paravermal cortex with low-impedance $(100-500 \mathrm{k} \Omega)$ tungsten-in-glass microelectrodes.

CNS implants. For stimulation of COCPs, a burr hole was made to allow chronic implantation of a bipolar stimulating electrode (animals BW3-BW5; Clarke Electromedical SN-100) or a bundle of six microwires (animal ME1) into the right cerebral peduncle (CP) (i.e., contralateral to the cerebellar recording sites) [stereotaxic coordinates: anteroposterior (AP), +6 or +7 ; mediolateral, +6 ; dorsoventral, -1 ). In cat ME1, two additional bundles of microwires were implanted into the contralateral pyramidal tract for stimulation of corticofugal pathways at AP levels +3 and -6 , whereas in cat BW5, a second bipolar electrode was implanted into the contralateral pyramidal tract at AP level -2 to allow monitoring of the descending tract volley. All wires were fed subcutaneously to connectors attached to the skull.

Stimulus parameters. In cats BW3-BW5, the ipsilateral or contralateral SR nerve was stimulated [single or double $0.1 \mathrm{msec}$ square pulses, $1 \mathrm{msec}$ interstimulus interval (ISI)] at twice the intensity to evoke a just detectable cerebellar field potential. In cat ME1, the stimulus intensity was just suprathreshold for evoking cutaneomuscular reflexes (40 and $50 \mu \mathrm{A}$ for the ipsilateral and contralateral SR nerves, respectively). For contralateral CP stimulation, a single pulse (ME1) or triple pulses (BW3-BW5; 1 msec 
ISI) were delivered at an intensity ranging from 0.08 to $0.6 \mathrm{~mA}$. No systematic differences were found using different stimulus parameters. In all cases, pulse width was $0.1 \mathrm{msec}$ to minimize activation of cell bodies.

Stimulus protocols during recording. During locomotion, either ipsilateral SR or contralateral CP stimulation was used to evoke activity in SOCPs and COCPs, respectively. In cats BW3-BW5, stimuli were delivered once every $1.5 \mathrm{sec}$, resulting in a pseudorandom delivery with respect to different phases of the step cycle (see Fig. 4C). Data for SR and CP stimulation were collected from the same cerebellar recording site on the same day, and during the same recording session whenever possible. In cat ME1, stimuli were triggered with different delays after onset of EMG activity in cleidobrachialis. SR stimulation was delivered every third step, whereas CP stimulation was delivered every second step, with the stimuli being delivered in consecutive bouts of locomotion during the same recording session. Note that in all experiments, only SR or CP was stimulated during the same bout of locomotion. For all animals, cerebellar responses evoked by 150-300 stimulus trials were collected during each period of walking. When paired stimuli were delivered (for example, CP as the test stimulus followed by SR as the conditioning stimulus), the animals were either sitting or standing quietly at rest.

Recording arrangements. Filter settings for recording evoked cerebellar field potentials were $30 \mathrm{~Hz}$ to $2.5 \mathrm{kHz}$ (BW3-BW5) or $3 \mathrm{~Hz}$ to $3 \mathrm{kHz}$ (ME1), and $1-3 \mathrm{kHz}$ when unitary activity was monitored. For EMG signals, the filter settings were $30 \mathrm{~Hz}$ to $2.5 \mathrm{kHz}$ and $300 \mathrm{~Hz}$ to $10 \mathrm{kHz}$ for the nerve volley. For the Bristol experiments (BW3-BW5), all signals were digitized on-line by customized software running on a CED 1401 Plus computer interface unit (Cambridge Electronic Design, Cambridge, UK). The sampling rates were $2.5 \mathrm{kHz}$ (BW3 and BW4) and $10 \mathrm{kHz}$ (BW5) for the fields, units, and EMG and $20 \mathrm{kHz}$ for the nerve volley. For the Montreal experiment (ME1), all signals were captured through a custom-built interface system (sampling rate, $2 \mathrm{kHz}$ ). In all experiments, the amplitude of individual nerve compound action potentials was measured peak to peak, and the size of individual cerebellar field potentials was measured as the area (millivolts $\times$ milliseconds) under each response from onset to offset of the initial waveform (Apps et al., 1997). Each measurement was obtained by manually placing cursors at the start and end of individual responses (as determined by a clear positive or negative deflection from baseline and a return to baseline) and the computer calculating the area of the intervening waveform. In two cases in animal ME1, large mossy fiber-related potentials preceded the climbing fiber potentials, and peak-to-peak amplitude was measured (Apps et al., 1990, 1997).

Data analysis. Individual step cycles were normalized and divided into 10 bins of equal duration (step 10ths). Cerebellar responses evoked by stimuli delivered during a particular bin were pooled and averaged (usually 15-30 trials per bin), generating a step histogram showing the average size of evoked field potential for each step 10th. In animals BW3BW5, step histograms were constructed using onset of activity in triceps brachii as a marker of the beginning of the stance phase of the step cycle in the ipsilateral forelimb (Apps et al., 1990, 1995). In ME1, the histograms were constructed relative to onset of activity in cleidobrachialis, which marks the start of the swing phase, but to aid comparison between data, these have been adjusted to show the step histograms relative to onset of stance. For the purpose of making statistical comparisons between step histograms, stance is taken as step 10ths $1-7$, and swing is taken as step 10ths 8-10. This usage of the terms stance and swing is an approximate one, because footfall and footlift occur partway through step 10ths 1 and 7, respectively.

In most cases, there was a progressive change in response size over the course of the step cycle, so only one peak (defined as the step 10th with the largest mean size of response) was evident throughout the step cycle. However, in some cases, two peaks could be identified in different phases of the step cycle because there were two step 10ths with large responses similar in size, separated by three or more bins containing smaller responses.

To assess the depth of modulation in individual step histograms, a modulation index was calculated using the following formula: $1-[(\mathrm{av}-$ erage response size in the smallest step 10th)/(average response size in the

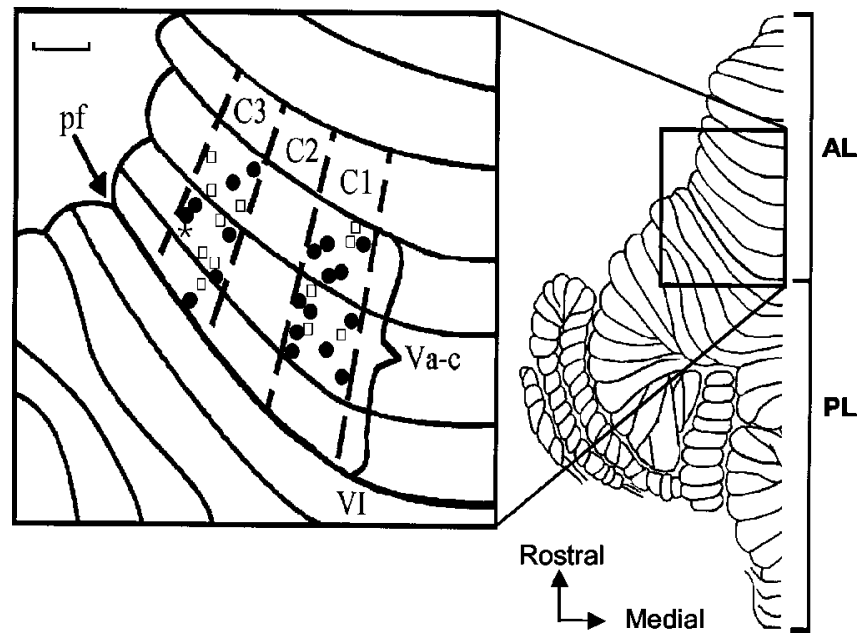

Figure 2. Distribution of cerebellar recording sites. Dorsal view of the left side of the unfolded cat cerebellum (modified from Larsell, 1953). The box shows an enlarged view of the anterior lobe (lobule $\mathrm{Va}-\mathrm{Vc}$ ) with the approximate location of individual recording sites in relation to the boundaries of paravermal zones C1-C3 on the cortical surface. Filled circles indicate microwire sites; open squares indicate microelectrode sites. The asterisk indicates a microelectrode penetration where two recording sites were obtained at different cortical depths. AL, Anterior lobe; pf, primary fissure; PL, posterior lobe. Scale bar, $1 \mathrm{~mm}$.

largest step 10th)]. This index takes a value of 1 when there is a part of the step cycle when no response is evoked (i.e., maximum depth of modulation) and a value of zero when modulation is absent.

Histology. After termination (usually $\sim 6$ weeks after the initial operation), the animals were deeply anesthetized with barbiturate and an electrolytic lesion made at the site of the bipolar stimulating electrode in the $\mathrm{CP}$ (positive $0.8 \mathrm{~mA}$ DC current, $\sim 60 \mathrm{sec}$ duration). The animals were then perfused transcardially with $0.9 \%$ heparinized saline and then $4 \%$ paraformaldehyde and $10 \%$ sucrose. The cerebellum and brainstem were removed, and a series of $100 \mu \mathrm{m}$ sagittal and transverse sections were prepared, respectively, for histological examination to verify the location of: (1) the microwires and microelectrode tracks in cerebellar lobule $\mathrm{Va}-\mathrm{Vc}$; (2) the stimulating electrode in the contralateral $\mathrm{CP}$, ranging in different experiments from AP level +6 to +7.5 (see Fig. 3); and (3) the recording electrode (animal BW5) in the contralateral pyramidal tract at AP level -0.9.

\section{Results}

Evoked field potentials were recorded at a total of 33 cerebellar cortical recording sites in four animals (19 microwire and 14 microelectrode sites). Because responses obtained with the two recording techniques produced very similar results, the data are considered together. In all animals, contralateral and ipsilateral SR stimulation was tested to determine the location of different recording sites with respect to the zonal organization of the cerebellar cortex. In accordance with many previous studies (Ekerot and Larson, 1979a,b; Trott and Apps, 1991), individual sites were identified as located within the $\mathrm{C} 1$ zone $(n=17)$ or C3 zone $(n=$ 16) by the presence of relatively short-latency field potentials to ipsilateral SR stimulation only (onset, 9-15 msec) and by their location in the medial and lateral parts of the paravermal cortex, respectively (Fig. 2). A few recording sites were also located in the intervening $\mathrm{C} 2$ zone, but these are not considered further here. Responses evoked by CP stimulation did not show any relation between zonal location and onset latency (range, 10-14 msec for individual sites).

For CP stimulation, the stimulus intensities used were likely to result in the spread of current in the CNS $\leq 1.8 \mathrm{~mm}$ from the cathode (usually considerably less) (Ranck, 1975). At the AP lev- 


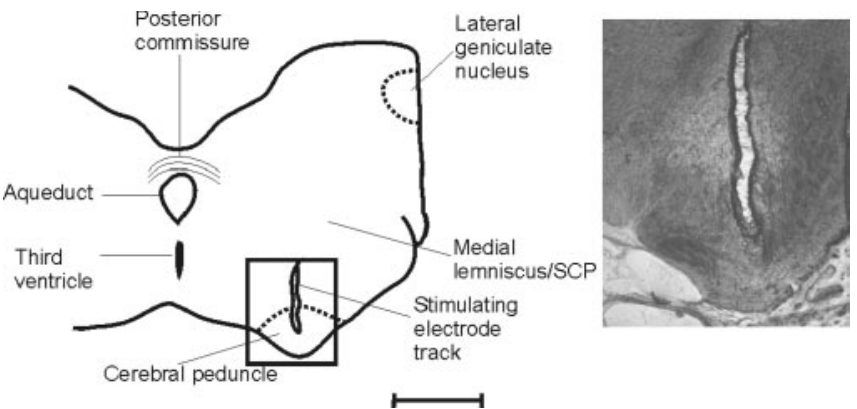

Figure 3. Histological location of the CP stimulation site. Camera lucida drawing of a transverse section of the midbrain (BW5) at approximately AP +6.5 . The inset shows a higherpower photomicrograph of a track made by the bipolar stimulating electrode. Scale bar, $\sim 3$ $\mathrm{mm}$ for low-power outline; $1 \mathrm{~mm}$ for photomicrograph.

els, where the rostral stimulating electrodes were implanted into the contralateral $\mathrm{CP}$, the medial lemniscus and superior cerebellar peduncle (SCP) are located $>3 \mathrm{~mm}$ dorsal to the positioning of the electrode tip (Fig. 3 ) and $\sim 4 \mathrm{~mm}$ dorsomedial from the red nucleus (Snider and Niemer, 1961). Thus, it is highly unlikely that such structures were activated directly. However, the possibility that SCP axon collaterals to zona incerta were stimulated cannot be fully excluded, although such collaterals are likely to be of small diameter, requiring a higher stimulus intensity to activate. In ME1, qualitatively similar results were obtained by stimuli delivered in the $\mathrm{CP}$ and in the pyramid in the rostral medulla, so any involvement of SCP collaterals is not likely to have been a major factor in the present experiments. Therefore, it seems safe to assume that the central stimulation activated mainly (perhaps only) corticofugal fibers.

\section{Characteristics of evoked field potentials}

Sample responses, evoked at the same site by SR and CP stimulation, are illustrated in Figure 4. At five recording sites, the responses were negative going, consistent with field potentials recorded in the molecular layer (Eccles et al., 1967) (Fig. 4A,B). The remainder were positive going, consistent with responses recorded at or below the Purkinje cell layer (Fig. 4C). In every case, the responses were identified as climbing fiber field potentials by the following criteria: (1) They exhibited a highly characteristic waveform, including in some cases one or two secondary peaks on their falling phase at $\sim 2$ msec intervals. (2) They displayed trial-by-trial fluctuations in amplitude. In comparison, responses attributable to activity in mossy fibers are usually more stable in size (Eccles et al., 1966; Armstrong and Harvey, 1968). (3) The onset latency of the fields was always $>9 \mathrm{msec}$ and therefore later than any known direct pathways terminating as mossy fibers (cf. Ekerot and Larson, 1973). (4) The characteristic pattern of response of climbing fiber fields to a paired-pulse test was also used to help distinguish them from responses evoked by activity in short-latency mossy fiber paths. When two supramaximal stimuli are delivered at interstimulus intervals ranging from 10 to 100 msec, the second climbing fiber field is depressed (Fig. 5), whereas responses to activation by short-latency mossy fiber paths remain unaffected (cf. Eccles et al., 1966; Armstrong and Harvey, 1968). (5) The duration of the responses was always considerably shorter than those attributable to activity in longerlatency mossy fiber pathways (cf. Kennedy et al., 1966; Morissette and Bower, 1996). For SR and CP stimulation, responses ranged in duration from 2.6 to $5.9 \mathrm{msec}$ and 2.7 to $7.1 \mathrm{msec}$, respectively (SR mean, $4.5 \pm 1.2 \mathrm{SD}$; CP mean, $3.6 \pm 1.3 \mathrm{SD}$ ). No significant
A

B
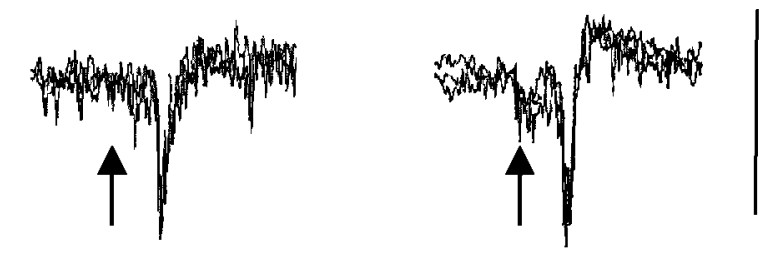

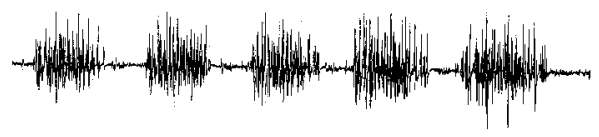

Field

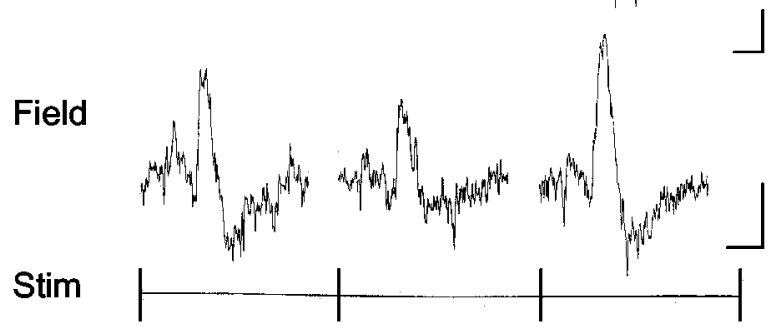

Stim

EMG

EMG

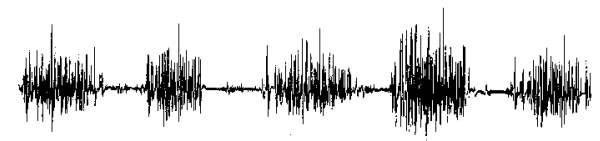

Field

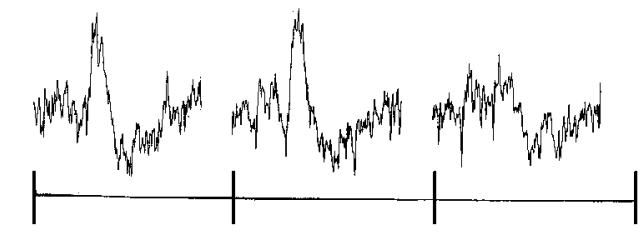

Figure 4. Sample climbing fiber field potentials. Extracellular recordings from the cerebellar cortex in the awake cat (3 sweeps superimposed) show sample climbing fiber field potentials obtained at the same paravermal recording site (in the molecular layer) and evoked by ipsilateral $\mathrm{SR}(A)$ or contralateral $\mathrm{CP}(B)$ stimulation. The stimulus was delivered at the time indicated by the arrow. Calibration: $0.2 \mathrm{mV}$, $50 \mathrm{msec}$. C, Evoked climbing fiber field potentials recorded during locomotion at a different paravermal recording site (located at or below the Purkinje cell layer). The EMG trace is continuous from the top left to the bottom right and displays activity in the ipsilateral forelimb extensor triceps brachii. Single-sweep traces below the EMG show individual cerebellar responses (field) evoked at 1.5 sec intervals by contralateral CP stimulation. Each single sweep is triggered at the onset of the stimulus (Stim). Calibration: EMG, $0.2 \mathrm{sec}, 0.5$ $\mathrm{mV}$; field, $10 \mathrm{msec}, 0.2 \mathrm{mV}$.

difference was found between the durations of SR- and CPevoked responses at the same site (Student's paired $t$ test; $p>$ $0.05 ; n=14$ comparisons). In contrast, long-latency mossy fiberrelated responses are much longer in duration (typically 20-30 msec) (Kennedy et al., 1966; Bloedel and Burton, 1970). (6) Definitive evidence that the fields represented climbing fiber activity was available at four $\mathrm{C} 1$ and five $\mathrm{C} 3$ zone recording sites, where it was possible to isolate and record the complex spike discharges of single Purkinje cells superimposed on the field potentials evoked by SR and CP stimulation. Complex spikes were evoked at onset latencies appropriate for the field potentials subsequently recorded at these sites (also see below). Thus, we conclude that the cerebellar field potentials evoked by SR and CP stimulation were 
generated by climbing fiber input (conveyed via SOCPs and COCPs, respectively).

Evidence that SR and CP stimulation activate a similar population of olive cells

In the present experiments, it was important to assess whether any step-related patterns of modulation of climbing fiber responses evoked by SR compared with CP stimulation at a particular cerebellar cortical recording site were attributable to changes in excitability of a common population of olive cells. Given that each Purkinje cell receives a single climbing fiber afferent and that the climbing fiber-Purkinje cell synapse is highly secure (Eccles et al., 1966; Llinas and Sugimori, 1980; Stuart and Hausser, 1994), it follows that a climbing fiber field potential generated in a group of Purkinje cells is the result of activation of a common group of olivary neurons (Apps et al., 1990).

Thus, conditioning stimuli can be used to indicate whether a similar population of olive cells is likely to be activated by the SR and $\mathrm{CP}$ stimulation. This is because a climbing fiber field evoked by one source of stimulation will leave the parent olive cells unresponsive to the other source of stimulation delivered during a subsequent $100 \mathrm{msec}$ time window. This possibility was tested at five recording sites. At four sites, the SR (test) stimulus was preceded at different intervals by $\mathrm{CP}$ stimulation (the conditioning stimulus). In every case, the test response was depressed relative to controls at short interstimulus intervals but exhibited at least partial recovery at an interstimulus interval of $120 \mathrm{msec}$ (Fig. 5A). The reverse combination of stimulus presentations (SR as the conditioning stimulus followed by CP stimulation as the test stimulus) was also investigated at three recording sites (two of the same sites tested above, plus one other), resulting in a similar response profile (Fig. 5B).

For most of the recording sites in which conditioning was performed (and for two additional sites), it was also possible to study the effect of paired stimuli delivered either to CP or SR (the paired-pulse test) (Fig. 5C,D). As in the conditioning experiments, the second response was smaller than the first and recovered progressively as the interstimulus interval was lengthened. Also consistent with the conditioning experiments was the finding that the second response was not completely abolished at the shortest interstimulus interval used, implying that not all olivary cells were activated by the first stimulus (on average, the conditioning and paired-pulse test responses were reduced by 71 and $68 \%$, respectively, at an interstimulus interval of $20 \mathrm{msec}$ ). Thus, the climbing fiber activity showed a reduction but not abolition of the second (test) response. This may be a result of changes in the intrinsic excitability of olivary neurons (cf. Llinas and Sasaki, 1989) and/or our use of submaximal stimulus intensities (typically, twice the threshold for evoking a detectable cortical response) (cf. Allen et al., 1974). Note also that for the paired-pulse test, facilitations were evident at longer stimulus intervals. This is an additional feature conforming with the electrophysiological

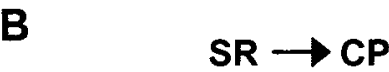

$\mathrm{CP} \rightarrow \mathrm{SR}$

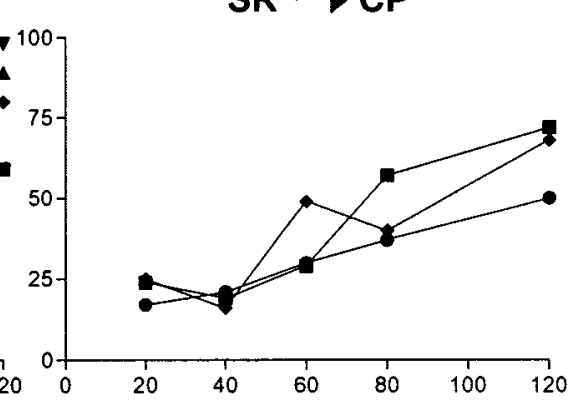

D

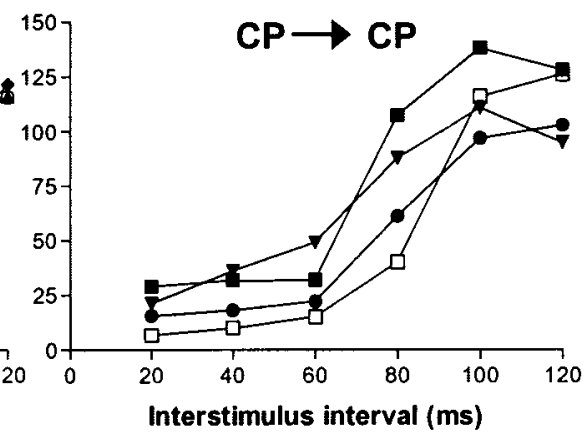

$\mathrm{SR} \rightarrow \mathrm{SR}$
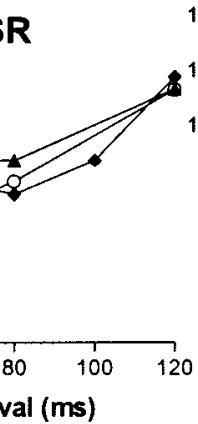

erstimulus interval (ms)

Figure 5. Effects of conditioning on a test response. Graphs show the size of test climbing fiber field potentials (expressed as a percentage of controls) plotted as a function of different interstimulus intervals after presentation of a conditioning stimulus. $A$, e climbing fiber field potential evoked by a test SR stimulus after a conditioning CP stimulus. Data are shown for fou is an average of 30 trials, and an average of 20 trials is shown in C and $D$. Corresponding symbols relate to the same recording site. CP, Contralateral CP; SR, ipsilateral SR.

properties of olivary neurons (Armstrong and Harvey, 1968; Llinas and Yarom, 1981).

Overall, these findings are therefore consistent with the SR and $\mathrm{CP}$ stimulation evoking climbing fiber field potentials at the same recording site as a result of activation of a common group of olivary neurons (see Discussion for additional comments). This conclusion is also supported by the single-unit recordings, in which the same complex spikes were evoked by both SR and CP stimuli (data not shown).

\section{Patterns of modulation during locomotion}

C1 zone sites

A total of 17 sites were located in the $\mathrm{C} 1$ zone of lobule $\mathrm{V}$, from which climbing fiber field potentials evoked by $\mathrm{CP}$ stimulation were recorded during locomotion (12 microwire and five microelectrode sites). At 13 of these sites, responses evoked by SR stimulation were also studied during additional bouts of locomotion (see Materials and Methods). Figure 6, $A$ and $B$, shows step histograms constructed from data evoked by CP or SR stimulation for one sample $\mathrm{C} 1$ zone site. Substantial variations in mean size of response are evident during the course of the step cycle in the ipsilateral forelimb, and the overall pattern of modulation clearly differs for $\mathrm{CP}$ compared with SR stimulation.

At the site shown in Figure 6A, the largest mean size of response evoked by $\mathrm{CP}$ stimulation (time of maximum transmission) occurs in step 10th 4, equating to the E2 and early E3 phases of stance, whereas the smallest mean size of response (time of minimum transmission) occurs in step 10th 8 (equivalent to the F phase of swing). In contrast, an approximately inverse pattern 

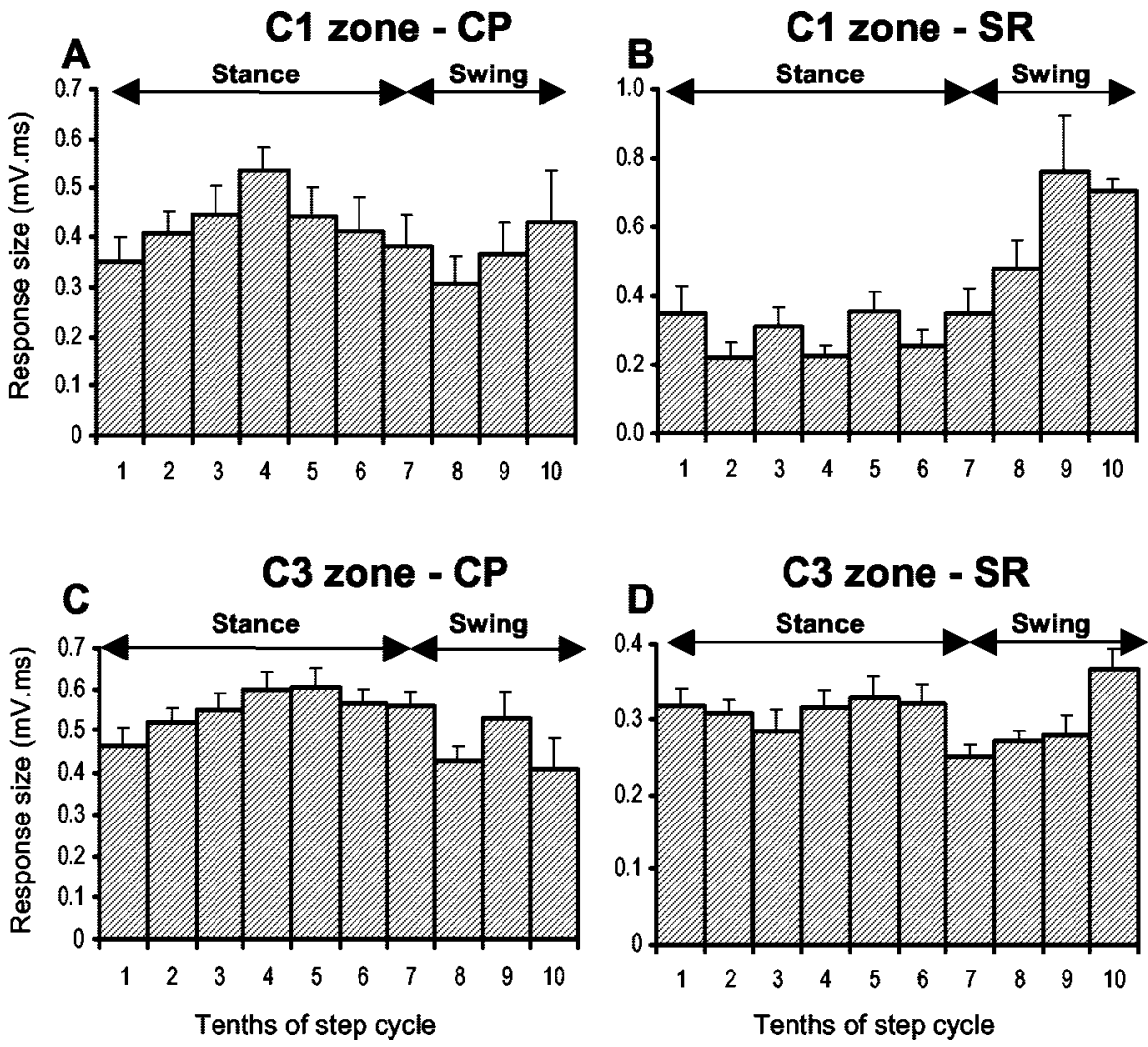

Figure 6. Sample step histograms. Step histograms show the mean size of the climbing fiber response ( + SEMs) evoked by stimulation of the contralateral $C P(A)$ and ipsilateral SR nerve $(B)$ at the same $C 1$ zone recording site for different 10ths of the step cycle (see Materials and Methods for additional details). ( and $D$, same as in $A$ and $B$ but recorded from a $(3$ zone site. In all cases shown, there was a statistically significant difference between the largest and smallest mean size of response (Student's $t$ test; $p<0.01)$. The periods of stance and swing are approximate timings for trajectory of the ipsilateral forelimb. $C P$, Contralateral CP; SR, ipsilateral SR.

of step-related modulation is observed for SR stimulation at the same site (Fig. 6B), with the largest and smallest mean size of response occurring in step 10ths 9 and 2 (swing and stance phases, respectively).

For step histograms from $16 \mathrm{C} 1$ zone sites (information on variance was not available for one site), a statistical comparison was made between the step 10th with the largest and smallest mean size of response evoked by CP stimulation, and in 15 of these, a significant difference was found (Student's unpaired $t$ test; $p<0.05$ in each comparison). Similarly, for 12 of these sites, it was possible to make a statistical comparison between the step 10th with the largest and smallest mean size of response evoked by SR stimulation, and in 11 of these, a significant difference was found (Student's unpaired $t$ test; $p<0.05$ in each comparison). Thus, for the overwhelming majority of available step histograms, there were significant differences in climbing fiber pathway excitability during locomotion.

When the modulation index values (see Materials and Methods for details) of individual step histograms are considered, an additional difference between SR and CP data is revealed. The CP step histogram in Figure $6 \mathrm{~A}$ has a modulation index of 0.43 . That is, the step 10th with the smallest mean size of response was $57 \%$ of the size of the response in the largest step 10th. In comparison, the modulation index for the SR step histogram for the same recording site is 0.71 (i.e., the step 10th with the smallest mean size of response was only $29 \%$ of the largest). Overall, the depth of modulation was usually lower (in 11 of 13 comparisons) for step histograms generated at a given site by CP rather than SR stimu- lation [modulation index ranged from 0.25 to 0.61 (mean $\pm \mathrm{SD}, 0.40 \pm 0.11$ ) for $\mathrm{CP}$ stimulation and from 0.38 to 0.72 (mean $\pm \mathrm{SD}, 0.56 \pm 0.18$ ) for SR stimulation]. This difference was statistically significant (Student's paired $t$ test; $p<0.05$ ).

In Figure 7, the data for all available $\mathrm{C} 1$ zone sites are pooled to show the time during the step cycle when CP stimulation evoked the largest and smallest mean size of response. The maximal response to $\mathrm{CP}$ stimulation occurred most frequently during step 10th 5 (Fig. 7A, mid-stance), and the minimum response occurred most frequently during step 10 th 1 (Fig. $7 B$, transition from swing to stance). In contrast, at the same sites, the maximum response to SR stimuli occurred most frequently during step 10ths 9 and 10 (Fig. 7C, swing), and the minimum response occurred most frequently during step 10th 3 (Fig. 7D, early stance). Statistical analysis confirmed that there was a highly significant difference between the distribution of maxima for CP and SR responses into, respectively, the stance and swing phases of the step cycle (Fisher's exact test; $p<0.0001$ ). In contrast, there was no significant difference between the distribution of minima (Fisher's exact test; $p>0.05$ ). However, CP minima tend to occur in late swing or at the transition from swing to stance (step 10ths 10 and 1 , respectively), whereas SR minima usually occur at other times during the step cycle. This difference in distribution is statistically significant (Bonferroni corrected $\chi^{2}$ test; $p<0.02)$. Furthermore, if the transitional step 10ths are excluded from the analysis (i.e., 10ths $2-6$ are tested against 10ths $8-10$ ), then significant differences in the distribution of step-phase timing of both maxima and minima for $\mathrm{CP}$ and SR responses are obtained (Fisher's exact test: maxima, $p<0.0001$; minima, $p<$ $0.03)$. Thus, significant differences are evident between SR and $\mathrm{CP}$ data, explicitly linked to the phases of the step cycle.

The pattern of step-related modulation for SR stimulation is in good agreement with more extensive results obtained previously for the same part of the C1 zone (Lidierth and Apps, 1990; Apps et al., 1995; Apps and Lee, 1999). The present study extends these findings by also monitoring at one recording site single-unit activity evoked by SR stimulation and charting the probability of occurrence of complex spikes in relation to different 10ths of the step cycle (CP stimulation was not tested for this cell). A clear peak in probability was found in the swing phase (step 10th 9) (Fig. 7E). This corresponds well with the pattern of step-related modulation observed with field potential recordings and shows that the latter method can reliably reflect changes in climbing fiber input to the cerebellar cortex (compare the step histograms in Figs. $6 B$ and $7 E$, which were constructed from field and singleunit data obtained at the same recording site). In accordance with previous findings (Armstrong et al., 1988), spontaneous complex spike activity recorded at this site was found to have no clear change in probability of occurrence in relation to the phases of the step cycle.

In summary, climbing fiber responses evoked by SR stimula- 

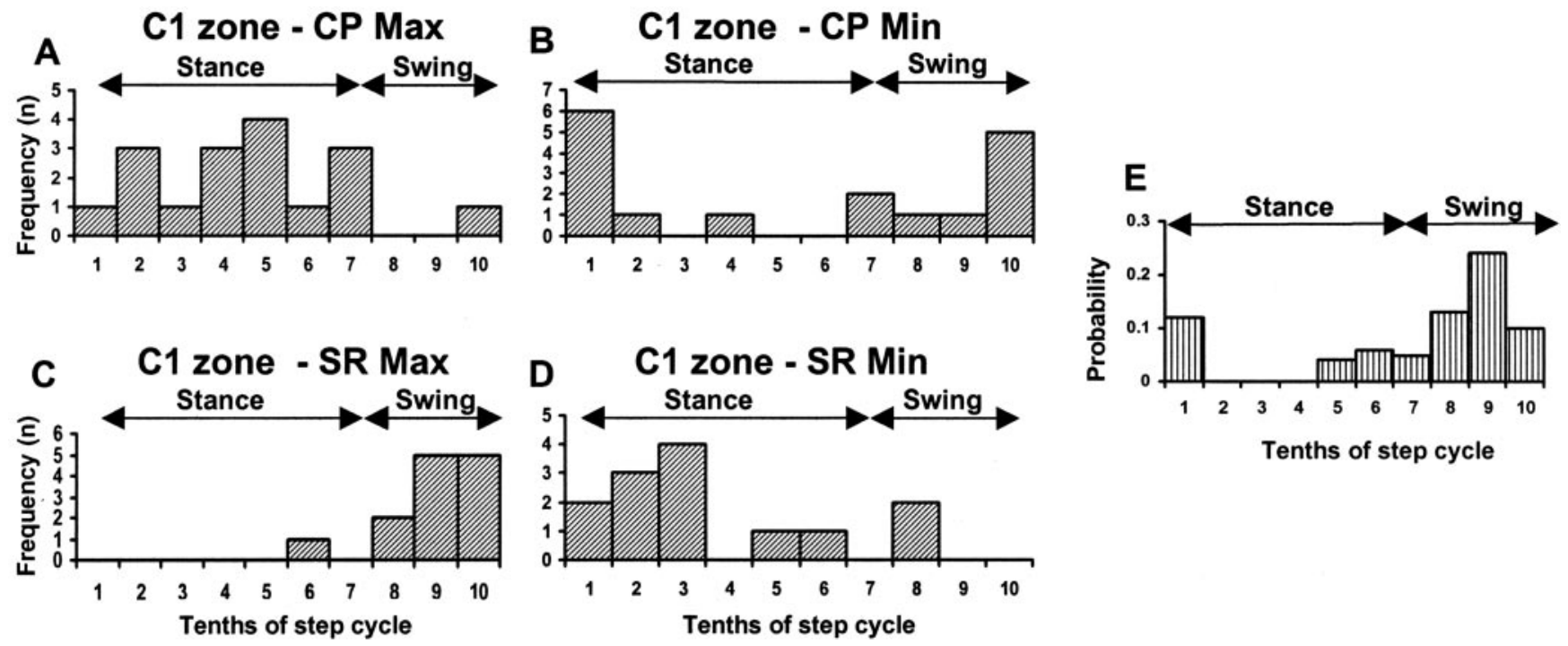

Figure 7. Summary data for all $\mathrm{C} 1$ zone sites. Frequency distributions show for all available $\mathrm{C} 1$ zone sites $(n=17)$ the time during the step cycle in the ipsilateral forelimb when mean size of response to contralateral $C P$ stimulation was largest $(A)$ and smallest $(B)$. ( and $D$, same as in $A$ and $B$ but for responses evoked by ipsilateral $S R$ stimulation and recorded from 13 of the same $(1$ zone sites. Eshows the probability of occurrence of complex spikes in response to ipsilateral SR stimulation for an individual Purkinje cell located in the C 1 zone. The recording site is the same as that shown in Figure 6, $A$ and $B$. For each step 10th, the probability of evoking a complex spike is based on 17-25 stimulus trials. Min, Minimum; Max, maximum. All other conventions and abbreviations are the same as in Figure 6.

tion (SOCPs) recorded in the $\mathrm{C} 1$ zone in lobule $\mathrm{V}$ of the cat cerebellum display best and worst transmission during the swing and stance phases of the step cycle in the ipsilateral forelimb, respectively. In marked contrast, climbing fiber responses evoked by CP stimulation (COCPs) recorded at the same $\mathrm{C} 1$ zone sites usually display a very different pattern of steprelated modulation, often with best transmission occurring during stance and worst transmission during swing.

\section{C3 zone sites}

A total of 16 recording sites were located in the cerebellar cortical C3 zone (seven microwire and nine microelectrode sites), and in every case, responses evoked by $\mathrm{CP}$ stimulation were recorded during locomotion. At 13 of these sites, the effect of SR stimulation was also studied during additional bouts of locomotion (Fig. 6C,D, sample step histograms from the same site). Overall, the timing of best and worst transmission obtained by CP stimulation exhibited a similar frequency distribution to the $\mathrm{C} 1$ zone data (compare Figs. $8 A, B$, $7 A, B)$. Maximum response size occurred most frequently during step 10th 5 (Fig. $8 \mathrm{~A}$, mid-stance), whereas minimum response size occurred most frequently during step 10th 9 (Fig. 8 B, swing). For step histograms from 15 sites, a statistical comparison was made between the step 10th with the largest and the smallest mean size of response, and in 13 of these, a significant difference was found (Student's unpaired $t$ test; $p<$ 0.05).

The corresponding frequency distributions for the same C3 zone sites but for histograms generated by SR stimulation are
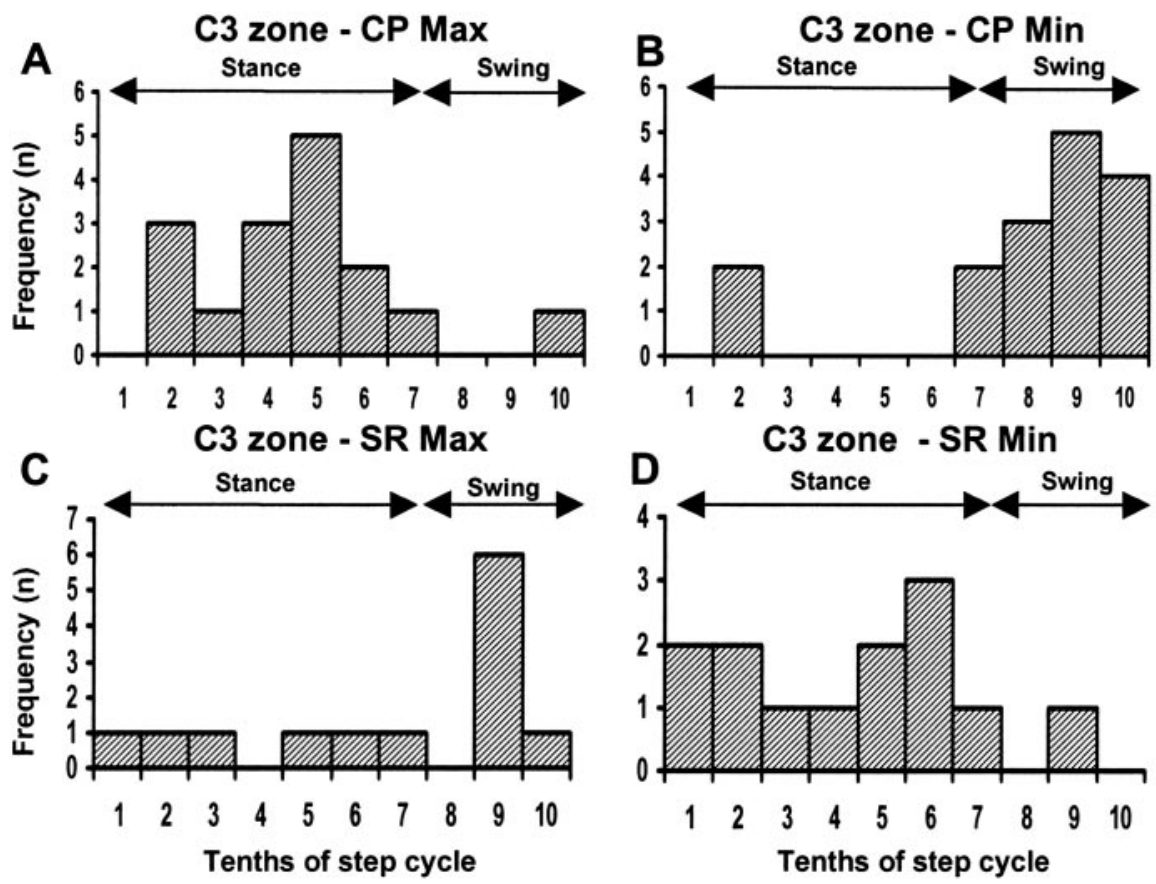

Figure 8. Summary data for all C 3 zone sites. Frequency distributions show for all available C 3 zone sites $(n=16)$ the time during the step cycle in the ipsilateral forelimb when mean size of response to contralateral $C P$ stimulation was largest $(A)$ and smallest ( $B$ ). ( and $D$, same as in $A$ and $B$ but for responses evoked by ipsilateral SR stimulation and recorded from 13 of the same $\mathrm{C} 3$ zone sites. For those recording sites in which more than one peak and trough was present in the step histogram, only the step 10ths with the largest and smallest responses have been considered. Min, Minimum; Max, maximum. All other conventions and abbreviations are the same as in Figure 6.

shown in Figure 8, $C$ and $D$. The time of largest mean response size was variable, although it occurred most frequently during swing (step 10th 9) (compare Figs. 8C, 7C). In five cases (38\%), two peaks (see Materials and Methods) were present in the step histograms. One occurred in mid- to late-stance and the second in swing. Timing of the smallest mean size of response was also variable but occurred most frequently during stance (Fig. $8 D$, 
step 10th 6). In 8 of 12 sites tested, a significant difference was found between the step 10th with the largest and smallest mean size of response evoked by SR stimulation (Student's unpaired $t$ test; $p<0.05$ in each comparison). Additional statistical analysis confirmed that the times of maxima and minima for CP compared with SR data were distributed differently between the stance and swing phases of the step cycle (Fisher's exact test; $p<$ 0.01 and $p<0.001$, respectively). Highly significant differences were also obtained when 10ths 1 and 7 were excluded from the analysis (Fisher's exact test: maxima, $p<0.0001$; minima, $p<$ $0.001)$.

Overall, the depth of modulation at C3 zone sites was usually lower (in 11 of 13 comparisons) for step histograms generated at a given site by CP compared with SR stimulation [modulation index ranged from 0.24 to 0.60 on average (mean \pm SD, $0.43 \pm$ 0.09 ) for CP step histograms and 0.27 to 0.80 (mean \pm SD, $0.44 \pm$ 0.16 ) for SR step histograms]. However, this difference was not statistically significant (Student's paired $t$ test; $p>0.05$ ).

In summary, $\mathrm{C} 3$ zone sites resembled the $\mathrm{C} 1$ data in a number of respects, including the timing of best and worst transmission for step histograms generated by CP stimulation (COCPs) and differences in step 10th timing and depth of modulation for $\mathrm{CP}$ compared with SR data. However, the one parameter that showed the greatest difference was the variability between individual sites in timing of best transmission for step histograms generated by SR stimulation (SOCPs). This implies a degree of functional heterogeneity between different parts of the $\mathrm{C} 3$ zone, and one possible reason for this is the presence of different microzones that receive climbing fiber input relayed by separate subpaths within the associated SOCPs (Ekerot and Larson, 1979a,b; Ekerot et al., 1991; Apps et al., 1995; Apps and Lee, 1999).

\section{Subzonal patterns of modulation}

In cats, the $\mathrm{C} 1$ and $\mathrm{C} 3$ zones comprise medial and lateral halves with climbing fiber input arising from different parts of the olive (Trott and Apps, 1991). This raises the possibility that different patterns of step-related modulation may be present in their respective spinal and cerebral inputs. In ME1, microelectrodes were advanced "blind" into the cortex, so the recording site loci were imprecise: they were identified principally on the basis of physiological responses. In BW3-BW5, microwires were chronically implanted under visual guidance so the cortical location (and physiology) of individual recording sites could be associated more reliably with zonal boundaries. Insufficient microwire sites were available to seek differences between medial and lateral subzones of the C3 zone. However, for the C1 zone, sites located either in the medial half (three sites) or in the lateral half (six sites) of the zone could be distinguished. The remaining three $\mathrm{C} 1 \mathrm{mi}-$ crowire sites were located centrally within the zone and therefore could not be reliably attributed to one or the other group.

There were no systematic differences between the times of smallest response for SOCP input to the medial and lateral groups of $\mathrm{C} 1$ sites, but the time of largest response suggested a small difference: for lateral C1 zone sites, largest responses occurred in step 10th 10 (in five of six sites, the exception occurred in step 10th 6), whereas for the three sites located in medial C1, largest responses occurred in step 10th 9 (two sites) or in step 10th 10 (one site). These results are consistent with previous findings (Apps et al., 1995). For the same recording sites, timing of smallest response in COCPs showed no systematic difference, whereas the results for the timing of the largest responses were also fairly mixed: for medial $\mathrm{C} 1$ zone sites, the largest responses occurred in the transition between stance and swing (step 10th 7) for two sites and in step 10th 3 for the other available site. For lateral C1 sites, the largest responses occurred in stance (step 10th 4 for three sites and step 10ths 3, 5, or 6 for the remainder). In summary, medial and lateral subzones in C1 would (at least on the basis of the present findings) appear not to have any pronounced differences in step-related pattern of modulation in their respective SOCPs and COCPs.

\section{Consistency of the probe stimulus during locomotion}

The step-related changes in climbing fiber response size observed in the present experiments may have occurred because of movement-related variations in efficacy of the probe stimulus. To control for this possibility, the compound action potential in the SR nerve in two animals (BW3 and BW4) and the volley in the pyramidal tract evoked by CP stimulation in a third animal (BW5) were monitored. The pyramidal tract volley was found to remain remarkably stable in size during locomotion, varying in amplitude by $\leq 3 \%$, suggesting constancy of the probe stimulus and little or no occlusive interaction with any spontaneous impulse traffic in the tract. Furthermore, no significant relationship was found between the amplitude of individual pyramidal tract volleys evoked by CP stimulation and the corresponding size of individual climbing fiber fields $\left(r^{2}<0.02 ; p>0.05\right.$; data from $n=2$ recording sessions). In comparison, the SR nerve volley was found to be more variable in size during locomotion, varying in amplitude by as much as $50 \%$. However, in no case was the size of the nerve volley in individual stimulus trials found to correlate with the corresponding (more substantial) fluctuations in the size of individual climbing fiber field potentials $\left(r^{2}<0.06 ; p>\right.$ 0.05 ; data from $n=7$ recording sessions). Thus, it is safe to conclude that the step-related changes in size of climbing fiber responses evoked by SR or CP stimulation are likely to be attributable to central changes in excitability rather than any steprelated changes in efficacy of the probe stimulus (cf. Apps et al., 1990; Apps and Lee, 1999) (also see Discussion for additional comments).

\section{Discussion}

The present study shows that a powerful modulatory influence(s) alters transmission in both descending COCPs and ascending SOCPs targeting the paravermal C1 and C3 zones in the cerebellar anterior lobe during locomotion in the awake cat, but that this pattern of modulation differs markedly in the two classes of climbing fiber input. Given the size and distribution of the evoked field potentials, the results also suggest that COCPs provide a potent excitatory input to climbing fibers in the behaving animal. Activation of such paths has only previously been demonstrated in anesthetized preparations (Miller et al., 1969; Allen et al., 1974; Andersson and Nyquist, 1983; Baker et al., 2001).

\section{Methodological considerations}

Our results depend on the modulations of field potential size, reflecting changes in central transmission of afferent signals rather than movement-related changes in stimulus efficacy or recording position. This is supported by a considerable amount of evidence. First, on a trial-by-trial basis, the amplitudes of the CP tract or SR nerve volleys showed little fluctuation in amplitude that did not correlate with the corresponding (more pronounced) changes in size of the evoked cerebellar responses. Second, constant current stimulation was used to activate the COCPs, and the stimulation electrode or stimulation bundle in the $\mathrm{CP}$ was implanted chronically and attached firmly to the skull, thereby minimizing any movement during locomotion: 
muscle response thresholds for stimuli delivered to these electrodes remained constant over many weeks, supporting this. Third, highly consistent results were obtained independently from two laboratories, despite the substantial differences in stimulation and recording techniques used.

Our results also depend on the cerebellar responses originating from climbing fiber pathways (rather than mossy fiber paths), and we present a range of evidence that this is indeed the case: the latencies, appearance, and properties of the field potentials; the recording of complex spikes with the same characteristics at the same locations; and the refractory and rebound features of the responses are all consistent with recording climbing fiber fields. A key additional finding was the observation that complex spike occurrence displayed a very similar pattern of step-phase dependence to climbing fiber field amplitude. Also, the responses were indistinguishable from climbing fiber fields recorded previously in anesthetized and awake animal preparations (Andersson and Nyquist, 1983; Apps and Lee, 2002).

Another issue that could influence the interpretation of the present findings is whether the CP and SR stimulation activated a common group of olive cells. The field-potential technique used is capable of recording subzonal activity, reflecting the activity of small groups of neighboring olive cells, possibly relating to two (perhaps more) adjacent cortical microzones. The different patterns of modulation in the SOCPs and COCPs might be explained by these separate groups of olivary neurons receiving (partly) independent descending and ascending inputs.

Several lines of evidence suggest, however, that this is unlikely to be the full explanation for our findings. First, within the rostral dorsal accessory olive (the site of relay for climbing fiber paths terminating in the medial $\mathrm{C} 1$ zone), descending and ascending projections overlap heavily (Berkley and Worden, 1978; Bull et al., 1990). We found that complex spikes of single Purkinje cells could be evoked by both SR and CP stimulation, providing unequivocal evidence that descending and ascending paths can converge on the same olivary neurons supplying climbing fibers to the relevant region of cortex, as reported previously (Provini et al., 1968; Miller et al., 1969; Leicht et al., 1973; Allen et al., 1974).

Second, there were no significant differences between the mean sizes of field potentials evoked by SR or CP stimulation during locomotion or rest (Student's paired $t$ test; $p>0.05$ for both comparisons). A difference might be expected if differentsized populations of olivary neurons were recruited by the two sources of stimulation. Third, the time of maximum response in SOCPs was similar for recording sites distributed throughout the $\mathrm{C} 1$ zone, suggesting that any SOCP subpaths targeting individual cortical microzones within $\mathrm{C} 1$ do not differ markedly in their patterns of step-related modulation. If there was partial overlap with COCPs, then a significant proportion of these sites would be expected to display the same time of maximum response as for CP stimulation, but this was the case in only 1 of 13 sites. Finally, if separate groups of olive cells were responsible for the different patterns of modulation, it might be expected that in the conditioning experiments, the test response would be essentially unaffected, especially at short interstimulus intervals. In contrast, the test response was on average $71 \%$ smaller at an interstimulus interval of $20 \mathrm{msec}$ (cf. Allen et al., 1974).

Thus, on the basis of the available evidence, it seems unlikely that small groups of olivary neurons receiving only partly overlapping ascending and descending inputs are the only factor responsible for explaining the differences we observed in the pattern of step-related modulation between SOCP and COCP inputs to individual recording sites. The findings can be more readily explained by the possibility that separate influences act on the relevant spinal and cerebral paths before their convergence.

\section{Possible sites of modulation}

The anatomical organization of COCPs targeting the $\mathrm{C} 1$ and $\mathrm{C} 3$ zones is not well established. However, in the cat, indirect pathways from the cerebral cortex to the appropriate region of the olive involving relays within brainstem sites have been reported (Andersson, 1984a; Kawamura and Onodera, 1984), whereas direct cerebro-olivary projections are thought to be sparse (SaintCyr, 1983). For SOCPs targeting the same zones, both direct and indirect pathways via the spinal cord and the dorsal column nuclei have been well documented (for review, see Apps, 1999).

Regardless of their origin, the COCP and SOCP climbing fiber responses share a common final pathway from the olive to the cerebellar cortex (Provini et al., 1968; Miller et al., 1969; Leicht et al., 1973; Rowe, 1977; Andersson and Nyquist, 1983). The pattern of innervation of olivary neurons by inhibitory and excitatory afferents is random, with no obvious preference for one type of terminal targeting intraglomerular or extraglomerular dendrites (de Zeeuw et al., 1998). Furthermore, detailed ultrastructural surveys have provided no evidence for axo-axonic contacts within the olive that could provide the substrate for selective transmissibility of different inputs (Walberg, 1963; King, 1980; de Zeeuw et al., 1990). However, inhibitory afferents arising from the cerebellar nuclei and excitatory afferents arising from the mesencephalon generally target proximal and intermediate dendrites of olive cells (de Zeeuw et al., 1989, 1990), whereas ascending afferents generally terminate outside glomeruli on distal dendrites (Molinari, 1987). Thus, the possibility exists that SOCPs may be selectively gated-out at the level of the olive. Therefore, a contribution by inhibitory inputs to the olive in generating some of the step-related changes in excitability is a possibility. This includes projections from the cerebellar, cuneate, and parasolitary nuclei (Nelson and Mugnaini, 1989). Regarding the cerebellar nucleo-olivary projection, this may exert its greatest influence on excitability during the swing phase of the step cycle, because this is when interpositus neurons are most active during locomotion (Orlovsky, 1972; Armstrong and Edgley, 1984, 1988).

However, in the present experiments, the efficacy of the SR and CP stimulation was judged to be similar (the intensity of both were usually adjusted to twice the threshold for evoking a cerebellar response). Because SR and CP stimulation were capable of evoking large climbing fiber responses during swing and stance, respectively, this implies that the SR and CP probe stimuli could over-ride any inhibition within the olive, regardless of the phase of the step cycle when either stimulus was delivered (i.e., intrinsic changes in olivary excitability may be present, but preolivary effects would appear to be the more dominant influence during locomotion).

This is not to say that excitability of climbing fibers cannot be modulated within the olive, especially because powerful inhibitory mechanisms are known to exist (Andersson, 1984b; Weiss et al., 1990; Horn et al., 1998; Gibson et al., 2002). Perhaps these mechanisms are concerned more with regulating transmission of climbing fiber signals during behaviors other than locomotion or during the acquisition of new motor skills (Hesslow and Ivarsson, 1996; but see Apps and Lee, 2002). The nucleo-olivary pathway may also have a more subtle role, altering the synchrony between neighboring olive cells by changing the extent to which they are electrotonically coupled (Welsh et al., 1995; Lang et al., 1996; Ruigrok, 1997). 


\section{Functional considerations}

The functional significance of the different patterns of modulation in SOCPs and COCPs remains to be determined. However, an important theoretical concept in motor control is the notion that the CNS generates an internal representation of the operation of the motor system to assist in planning, control, and learning of new movements (Wolpert et al., 1995). The internal representation may take the form of a forward model, in which a "state estimator" (thought to be the cerebellum) integrates sensory and motor signals to generate predictions. If the reliability of information content in these two sources varies, then it would be desirable to alter the balance of reliance between them to minimize the overall uncertainty of the state estimate. Climbing fiber signals are usually considered to represent a system for modification of the model to optimize its predictive capacity. The different patterns of gating in COCPs and SOCPs might then reflect the changing usefulness of learning signals derived from descending motor pathways or peripheral afferents during stance and swing, respectively. The latter is at a time when cutaneous afferents from the paw are most likely to drive withdrawal reflexes and is therefore also consistent with the notion that SOCPs convey information relating to motor output (Garwicz, 2002).

\section{References}

Allen GI, Azzena GB, Ohno T (1974) Cerebellar Purkinje responses to inputs from sensorimotor cortex. Exp Brain Res 20:239-254.

Andersson G (1984a) Demonstration of a cuneate relay in a cortico-olivocerebellar pathway in the cat. Neurosci Lett 46:47-52.

Andersson G (1984b) Mutual inhibition between olivary cell groups projecting to different cerebellar microzones in the cat. Exp Brain Res 54:293-303.

Andersson G, Armstrong DM (1987) Complex spikes in Purkinje cells in the lateral vermis (b zone) of the cat cerebellum during locomotion. J Physiol (Lond) 385:107-134.

Andersson G, Nyquist J (1983) Origin and sagittal termination areas of cerebro-cerebellar climbing fibre paths in the cat. J Physiol (Lond) 337:257-285.

Apps R (1999) Movement-related gating of climbing fibre input to cerebellar cortical zones. Prog Neurobiol 57:537-562.

Apps R, Lee S (1999) Gating of transmission in climbing fibre paths to cerebellar cortical C1 and C3 zones in the rostral paramedian lobule during locomotion in the cat. J Physiol (Lond) 516:875-883.

Apps R, Lee S (2002) Central regulation of cerebellar climbing fibre input during motor learning. J Physiol (Lond) 541:301-317.

Apps R, Pardoe J (2001) Transmission in cerebro-olivocerebellar paths during locomotion. Soc Neurosci Abstr 27:70.5.

Apps R, Lidierth M, Armstrong DM (1990) Locomotion-related variations in excitability of spino-olivocerebellar paths to cat cerebellar cortical $c_{2}$ zone. J Physiol (Lond) 424:487-512.

Apps R, Hartell NA, Armstrong DM (1995) Step phase-related excitability changes in spino-olivocerebellar paths to the $c_{1}$ and $c_{3}$ zones in cat cerebellum. J Physiol (Lond) 483:687-702.

Apps R, Atkins MJ, Garwicz M (1997) Gating of cutaneous input to cerebellar climbing fibres during a reaching task in the cat. J Physiol (Lond) 502:203-214.

Armstrong DM, Edgley SA (1984) Discharges of nucleus interpositus neurones during locomotion in the cat. J Physiol (Lond) 351:411-432.

Armstrong DM, Edgley SA (1988) Discharges of interpositus and Purkinje cells of the cat cerebellum during locomotion under different conditions. J Physiol (Lond) 400:425-445.

Armstrong DM, Harvey RJ (1968) Responses to a spino-olivo-cerebellar pathway in the cat. J Physiol (Lond) 194:147-168.

Armstrong DM, Edgley SA, Lidierth M (1988) Complex spikes in Purkinje cells of the paravermal part of the anterior lobe of the cat cerebellum during locomotion. J Physiol (Lond) 400:405-414.

Baker MR, Javid M, Edgley SA (2001) Activation of cerebellar climbing fibres to rat cerebellar posterior lobe from motor cortical output pathways. J Physiol (Lond) 536:825-839.

Bauswein E, Kolb FP, Leimbeck B, Rubia FJ (1983) Simple and complex spike activity of cerebellar Purkinje cells during active and passive movements in the awake monkey. J Physiol (Lond) 339:379-394.

Berkley KJ, Worden IG (1978) Projections to the inferior olive of the cat. I. Comparisons of input from the dorsal column nuclei, the lateral cervical nucleus, the spino-olivary pathways, the cerebral cortex and the cerebellum. J Comp Neurol 180:237-252.

Bloedel JR, Burton JE (1970) Electrophysiological evidence for a mossy fiber input to the cerebellar cortex activated indirectly by collaterals of spinocerebellar pathways. J Neurophysiol 33:308-319.

Bull MS, Mitchell SK, Berkley KJ (1990) Convergent inputs to the inferior olive from the dorsal column nuclei and pretectum in the cat. Brain Res 525:1-10.

de Zeeuw CI, Holstege JC, Ruigrok TJ, Voogd J (1989) An ultrastructural study of the GABAergic, cerebellar, and mesodiencephalic innervation of the cat medial accessory olive: anterograde tracing combined with immunocytochemistry. J Comp Neurol 284:12-35.

de Zeeuw CI, Holstege JC, Ruigrok TJH, Voogd J (1990) Mesodiencephalic and cerebellar terminals terminate upon the same dendritic spines in the glomeruli of the cat and rat inferior olive: an ultrastructural study using a combination of $\left[{ }^{3} \mathrm{H}\right]$ leucine and wheat germ agglutinin coupled horseradish peroxidase anterograde tracing. Neuroscience 34:645-655.

de Zeeuw CI, Simpson JI, Hoogenraad CC, Galjart N, Koekkoek SK, Ruigrok TJ (1998) Microcircuitry and function of the inferior olive. Trends Neurosci 21:391-400.

Drew T (1993) Motor cortical activity during voluntary gait modifications in the cat. I. Cells related to the forelimbs. J Neurophysiol 70:179-199.

Eccles JC, Llinas R, Sasaki K (1966) The excitatory synaptic action of climbing fibres on the Purkinje cells of the cerebellum. J Physiol (Lond) 182:268-296.

Eccles JC, Ito M, Szentágothai J (1967) The cerebellum as a neuronal machine. New York: Springer.

Ekerot CF, Larson B (1973) Correlation between sagittal projection zones of climbing and mossy fibre paths in cat cerebellar anterior lobe. Brain Res 64:446-450.

Ekerot CF, Larson B (1979a) The dorsal spino-olivocerebellar system in the cat. I. Functional organization and termination in the anterior lobe. Exp Brain Res 36:201-217.

Ekerot CF, Larson B (1979b) The dorsal spino-olivocerebellar system in the cat. II. Somatotopical organization. Exp Brain Res 36:219-232.

Ekerot CF, Garwicz M, Schouenborg J (1991) Topography and nociceptive receptive fields of climbing fibres projecting to the cerebellar anterior lobe in the cat. J Physiol (Lond) 441:257-274.

Garwicz M (2002) Spinal reflexes provide motor error signals to cerebellar modules-relevance for motor coordination. Brain Res Brain Res Rev 40:152-165.

Gellman R, Gibson AR, Houk JC (1985) Inferior olivary neurons in the awake cat: detection of contact and passive body displacement. J Neurophysiol 54:40-60.

Gibson AR, Horn KM, Stein JF, Van Kan PL (1996) Activity of interpositus neurons during a visually guided reach. Can J Physiol Pharmacol 74:499-512.

Gibson AR, Horn KM, Pong M (2002) Inhibitory control of olivary discharge. Ann NY Acad Sci 978:219-231.

Hesslow G, Ivarsson M (1996) Inhibition of the inferior olive during conditioned responses in the decerebrate ferret. Exp Brain Res 110:36-46.

Horn KM, Van Kan PL, Gibson AR (1996) Reduction of rostral dorsal accessory olive responses during reaching. J Neurophysiol 76:4140-4151.

Horn KM, Hamm TM, Gibson AR (1998) Red nucleus stimulation inhibits within the inferior olive. J Neurophysiol 80:3127-3136.

Kawamura K, Onodera S (1984) Olivary projections from the pretectal region in the cat studied with horseradish peroxidase and tritiated amino acids axonal transport. Arch Ital Biol 122:155-168.

Kennedy TT, Grimm RJ, Towe AL (1966) The role of cerebral cortex in evoked somatosensory activity in cat cerebellum. Exp Neurol 14:13-32.

King JS (1980) Synaptic organization of the inferior olivary complex. In: The inferior olivary nucleus: anatomy and physiology (Courville J, de Montigny C, Lamarre Y, eds), pp 1-33. New York: Raven.

Kolb FP, Rubia FJ (1980) Information about peripheral events conveyed to the cerebellum via the climbing fiber system in the decerebrate cat. Exp Brain Res 38:363-373.

Lang E, Sugihara I, Llinas R (1996) GABAergic modulation of complex 
spike activity by the cerebellar nucleoolivary pathway in rat. J Neurophysiol 76:255-275.

Larsell O (1953) The cerebellum of the cat and the monkey. J Comp Neurol 99:135-199.

Leicht R, Rowe MJ, Schmidt RF (1973) Cutaneous convergence on to the climbing fibre input to cerebellar Purkinje cells. J Physiol (Lond) 228: 601-618.

Lidierth M, Apps R (1990) Gating in the spino-olivocerebellar pathways to the $\mathrm{c}_{1}$ zone of the cerebellar cortex during locomotion in the cat. J Physiol (Lond) 430:453-469.

Llinas R, Sasaki K (1989) The functional organization of the olivo-cerebellar system as examined by multiple Purkinje cell recordings. Eur J Neurosci 1:587-602.

Llinas R, Sugimori M (1980) Electrophysiological properties of in vitro Purkinje cell dendrites in mammalian cerebellar slices. J Physiol (Lond) 305:197-213.

Llinas R, Yarom Y (1981) Electrophysiology of mammalian inferior olivary neurones in vitro. Different types of voltage-dependent ionic conductances. J Physiol (Lond) 315:549-567.

Miller S, Nezlina N, Oscarsson O (1969) Projection and convergence patterns in climbing fibre paths to cerebellar anterior lobe activated from cerebral cortex and spinal cord. Brain Res 14:230-233.

Molinari HH (1987) Ultrastructure of the gracile nucleus projection to the dorsal accessory subdivision of the cat inferior olive. Exp Brain Res 66:175-184.

Morissette J, Bower JM (1996) Contribution of somatosensory cortex to responses in the rat cerebellar granule cell layer following peripheral tactile stimulation. Exp Brain Res 109:240-250.

Nelson BM, Mugnaini E (1989) Origin of GABAergic inputs to the inferior olive. Exp Brain Res Ser 17:86-107.

Orlovsky GN (1972) Work of the neurones of the cerebellar nuclei during locomotion. Biofizika 17:1177-1185.

Provini L, Redman SJ, Strata P (1968) Mossy and climbing fiber organization in the anterior lobe of the cerebellum activated by forelimb and hindlimb areas of the sensorimotor cortex. Exp Brain Res 6:216-233.
Ranck JB (1975) Which elements are excited in electrical stimulation of mammalian central nervous system: a review. Brain Res 98:417-440.

Rowe MJ (1977) Cerebral cortical areas associated with the activation of climbing fibre input to cerebellar Purkinje cells. Arch Ital Biol 115:79-93.

Ruigrok TJ (1997) Cerebellar nuclei: the olivary connection. Prog Brain Res 114:167-192.

Saint-Cyr JA (1983) The projection from the motor cortex to the inferior olive in the cat. An experimental study using axonal transport techniques. Neuroscience 10:667-684.

Simpson J, Wylie DR, de Zeeuw CI (1996) On climbing fiber signals and their consequence(s). Behav Brain Sci 19:384-398.

Smith SS, Chapin JK (1996) The estrous cycle and the olivo-cerebellar circuit. II. Enhanced selective sensory gating of responses from the rostral dorsal accessory olive. Exp Brain Res 111:385-392.

Snider RS, Niemer WT (1961) A stereotaxic atlas of the cat brain. Chicago: University of Chicago.

Stuart G, Hausser M (1994) Initiation and spread of sodium action potentials in cerebellar Purkinje cells. Neuron 13:703-712.

Teune TM, van der Burg J, de Zeeuw CI, Voogd J, Ruigrok TJ (1998) Single Purkinje cell can innervate multiple classes of projection neurons in the cerebellar nuclei of the rat: a light microscopic and ultrastructural tripletracer study in the rat. J Comp Neurol 392:164-178.

Trott JR, Apps R (1991) Lateral and medial subdivisions within the olivocerebellar zones of the paravermal cortex in lobule $\mathrm{Vb} / \mathrm{c}$ of the cat anterior lobe. Exp Brain Res 87:126-140.

Walberg F (1963) An electron microscopic study of the inferior olive of the cat. J Comp Neurol 120:1-17.

Weiss C, Houk JC, Gibson AR (1990) Inhibition of sensory responses of cat inferior olive neurons produced by stimulation of red nucleus. J Neurophysiol 64:1170-1185.

Welsh JP, Lang EJ, Sugihara I, Llinas R (1995) Dynamic organization of motor control within the olivocerebellar system. Nature 374:453-457.

Wolpert DM, Ghahramani Z, Jordan MI (1995) An internal model for sensorimotor integration. Science 269:1880-1882. 